November 13, 2000

\title{
Effect of Pressure Transmission Lines on the Frequency Response of Pressure Transducers
}

\author{
G.J. Kirouac
}

This report was prepared as an account of work sponsored by the United States Government. Neither the United States, nor the United States Department of Energy, nor any of their employees, nor any of their contractors, subcontractors, or their employees, makes any warranty, express or implied, or assumes any legal liability or responsibility for the accuracy, completeness or usefulness of any information, apparatus, product or process disclosed, or represents that its use would not infringe privately owned rights. 


\title{
Effect of Pressure Transmission Lines on the Frequency Response of Pressure Transducers
}

\author{
GJ Kirouac \\ Lockheed Martin Corporation \\ P.O.Box 1072 \\ Schenectady, New York 12301
}

Keywords: Transient pressure measurements, frequency response model, data comparisons

\section{ABSTRACT}

It is well known that the length and diameter of the transmission lines between a pressure transducer and the pressure source can significantly affect the dynamic frequency response of the transducer. A new lumped parameter model has been developed to predict the time and frequency response of any number of different transducers connected in parallel in a manifold. While the model is simple to apply, it can provide quantitative information given the transducer and transmission line characteristic parameters. More importantly, the model can be used to evaluate the measured, in-situ response. This provides the natural frequency and the effective damping which can then be used to generate a frequency response curve. The model is also useful for designing a new pressure transmission system, which will have the required frequency response.

The model was qualified by comparison to measurements of the stepfunction pressure response of a number of different transducers and test installations. With the aid of the model, the system resonant frequency and damping can be determined. Additional damping can be added if necessary to prevent ringing of the signal and to assure an accurate pressure measurement with a flat frequency response.
\end{abstract}

For all of the experimental systems evaluated in this work, the response at the natural frequency was significantly underdamped and ringing was observed. This means that to perform accurate measurements damping needs to be added to the system. It was observed that the use of flexible pressure lines versus hard lines does increase the damping and may therefore be useful in certain situations. Equations were developed to permit sizing an orifice to be added to the system to provide the necessary damping.

\section{NOMENCLATURE}

$\mathrm{P}_{\mathrm{a}, \mathrm{l}, \mathrm{m}}(\mathrm{t})$ Pressure at test section (a),manifold (I), transducer (m)

$m_{1}, X_{1}$ mass and displacement of fluid of density $\rho$ in the lines

$\mathrm{k}_{\text {eff }} \quad$ transducer spring constant $=\mathrm{A}^{2} \frac{\Delta P}{\Delta V}$

L,d line length and diameter

$\mathrm{T}_{\mathrm{I}} \quad$ transducer rise time

$\omega_{n}, f_{n}$ natural resonant frequency

$\mathrm{C}_{\mathrm{l}}, \mathrm{C}_{\mathrm{t}}$ damping coefficients for fluid lines,

$\mathrm{C}_{\text {eff }}$ transducer and total system

$\mu, \nu$ fluid viscosity and kinematic viscosity 


\section{Introduction}

The length and diameter of the transmission lines between a pressure transducer and the pressure source can significantly affect the dynamic frequency response of the transducer. As a general design practice, it is best to keep these lines as short as possible. Larger diameter transmission lines will also improve performance. In this paper, a lumped parameter, spring-mass-damper model of a multiple transducer and pressure line system is adapted from an earlier, more limited model in the literature (1). While the new model remains simple, it can provide quantitative information given the transducer and transmission line characteristic parameters: the spring constant, system damping and transducer rise time. More importantly, the model can be used to describe the measured, in-situ response of any one or a group of parallel connected transducers. This fitting of model to measurement provides two key parameters: the natural frequency and the effective in-situ damping. These parameters can subsequently be used to generate a frequency response curve. The model is also useful for designing a pressure transmission system which will have the required frequency response for a given test loop.

In the next section of this paper the development of the model is described. The most important results are analytical, closed form solutions for the time and frequency response of the system as a whole and also for each individual transducer. In Section 3 the development and calculation of model parameters are considered. These include the effective spring constant and the damping parameters. The spring constant, along with the mass of the fluid in the lines and the line length and diameter, determine the natural frequency which is an extremely important system characteristic. In the discussion of damping parameters, equations are developed to describe the damping due to viscous fluid friction forces in the lines and also irrecoverable pressure losses such as those due to an orifice in the system. This later pressure drop equation permits the selection of an orifice having just that loss factor needed to provide critical damping to an underdamped system which has undesirable oscillations. In Section 4, the results of the model are compared with measurements of the step-function response of transient pressure measurement systems. Specific new measurements were recently made to validate the models developed. Sections 3 and 4 also illustrate how the models can be used to design a transient pressure measurement system having the desired frequency response. In Section 5, a brief summary of results is presented.

\section{Description of the Model}

The system to be modeled consists of a pressure source to be measured (e.g. a test section differential pressure), a pair of pressure transmission lines each of length $\mathrm{L} / 2$ including the transducer manifold, and a number of pressure transducers connected in parallel at the manifold. The transducers each have a full scale rating of $\Delta P / \Delta V$ where $\Delta \mathrm{P}$ is the full-scale pressure and $\Delta \mathrm{V}$ is the full-scale displacement volume within the transducer. Each transducer also has a specific response time. The system is further simplified without loss of generality by representing the differential pressure as an absolute pressure, having both positive and negative values, at the end of a line of length L. This system will be modeled in two partitions. The first partition describes the system response and transfer function up to the manifold. This response becomes the driving function for each of the transducers. The second partition describes the response and transfer function of any pressure transducer taken by itself. A sketch of this system is provided in Figure 1.

The first segment can be modeled as a 2'nd order spring-mass-damper system. The mass is the total mass of the fluid in the lines, $m_{1}$. The spring constant $k_{\text {eff }}$ is determined by the full scale $\Delta \mathrm{P} / \Delta \mathrm{V}$ rating of each of the transducers connected in parallel (i.e. $\mathrm{k}_{\mathrm{eff}}=\Sigma \mathrm{k}_{\mathrm{i}}$ ). The damping coefficient, $\mathrm{C}_{\mathrm{eff}}$, results from the series combination of 
damping in the lines, $\mathrm{C}_{\mathrm{l}}$, and transducer damping, $\mathrm{C}_{\mathrm{t}}=\Sigma \mathrm{C}_{\mathrm{i}}$. The damping in the lines includes viscous forces due to the fluid motion as well as any other dissipative forces such as orifices or other components with unrecoverable pressure losses. $\mathrm{C}_{\text {eff }}$ is given by $\mathrm{C}_{\mathrm{t}} \mathrm{C}_{\mathrm{l}} /\left(\mathrm{C}_{\mathrm{t}}+\mathrm{C}_{\mathrm{l}}\right)$.

The system differential equation is,

$m_{l} \ddot{X}_{l}+C_{e f f} \dot{X}_{l}+k_{e f f} X_{l}=F_{a}$

Where $F_{a} / a$ is the absolute (differential) pressure at the test section. The transmission lines have area, a. The variable $X_{l}$ refers to an incremental displacement of the fluid in the lines. The variable $X_{1}$ can be related to the indicated pressure $\mathrm{P}_{\mathrm{i}}$ at the port of any transducer by noting,

$$
\left(X_{l} a\right) \Delta P / \Delta V \mid F u l l=P_{i}
$$

This leads to a new differential equation,

$$
\ddot{P}_{i}+\beta_{l} \dot{P}_{i}+\omega_{n}{ }^{2} P_{i}=\omega_{n}{ }^{2} P_{a}
$$

Where $\beta_{\mathrm{l}}=\mathrm{C}_{\text {eff }} / \mathrm{m}_{1}$ and $\omega_{\mathrm{n}}=\left(\mathrm{k}_{\mathrm{eff}} / \mathrm{m}_{1}\right)^{1 / 2}$.

This differential equation can be

transformed to the algebraic equation,

$$
\left(S^{2}+S \beta_{1}+\omega_{n}{ }^{2}\right) P_{i}(S)=\omega_{n}{ }^{2} P_{a}(S)
$$

The complex roots of this second order equation are well known and lead to solutions which may be underdamped (i.e., oscillatory), critically damped $\left(\beta / 2=1 / \omega_{\mathrm{n}}\right)$, or overdamped (exponentially decaying).

When this hydraulic system is underdamped the general solution in the time domain is of the form:

$$
P_{i}(t)=\exp \left(-\beta_{l} t / 2\right)\left\{A \sin \omega_{r} t+B \cos \omega_{r} t\right\}+P_{s s}
$$

With $\omega_{r}=\sqrt{\left(\beta_{l} / 2\right)^{2}-\omega_{n}{ }^{2}}$

The constants $A$ and $B$ are determined by initial conditions and $P_{s s}$ is the steady state solution. The particular solution for a step function input of magnitude $P_{0}$, which will subsequently be compared with measurements, is given by,

$$
P_{i}(t)=P_{0}\left[1-\exp \left(-\beta_{l} t / 2\right) \cos \omega_{r} t\right] \text { (6) }
$$

This function represents the transmission line response that would be seen in the manifold as the driving function applied to the port of an ideal transducer having a negligible mass diaphragm and instantaneous response time.

The undamped natural frequency, $\omega_{n} / 2 \pi$, is given by $f_{n}=\left(k_{\text {eff }} / m_{1}\right)^{1 / 2} / 2 \pi$. Which in engineering units is (Zabriskie et.al.,1982),

$\mathrm{f}_{\mathrm{n}}=28.8\left(\mathrm{~d}^{2} / \rho \mathrm{L} * \Delta \mathrm{P} / \Delta \mathrm{V} \mathrm{leff}_{\mathrm{ff}}\right)$

Where

$\mathrm{f}_{\mathrm{n}}=$ natural frequency $(\mathrm{Hz})$

$\mathrm{d}=$ transmission line I.D. (in)

$\mathrm{L}=$ total line length ( $\mathrm{ft}$ both lines)

$\Delta \mathrm{P} / \Delta \mathrm{V} \mathrm{l}_{\mathrm{eff}}=$ transducer full scale response $\left(\mathrm{psi} / \mathrm{in}^{3}\right)^{3}$

$\rho=$ density of the fluid medium $\left(\mathrm{lb} / \mathrm{ft}^{3}\right)$

With no damping in the system $\left(\beta_{1}=0\right)$, the transfer function $R_{1}(f)=P_{i}(f) / P_{a}(f)$ is given by:

$\mathrm{R}_{1}(\mathrm{f})=1 /\left|1-\left(\mathrm{f} / \mathrm{f}_{\mathrm{n}}\right)^{2}\right|$

The measured response approaches the true applied differential pressure only for frequencies well below the natural frequency $\left(\mathrm{f}<\mathrm{f}_{\mathrm{n}}\right)$.

In practice, all physical systems have some damping, $\beta$. This includes the viscous damping due to fluid motion within the pressure lines as well as other dissipative forces. With finite damping the system response function (transfer function) becomes,

$R_{1}(f)=1 /\left\{\left[1-\left(f / f_{n}\right)^{2}\right]^{2}+(2 \pi f \tau)^{2}\right\}^{1 / 2}$

With $\tau=2 / \beta_{1}$.

The second segment of the system is comprised of one of the individual transducers. The pressure measured at the transducer, $\mathrm{P}_{\mathrm{m}}$, can also be modeled as a spring-mass-damper with the mass being that of the transducer moving member (e.g. the diaphragm). The damping corresponds to the transducer rise time, and the spring constant $\mathrm{k}$ is $\mathrm{A}^{2} \Delta \mathrm{P} /\left.\Delta \mathrm{V}\right|_{\text {Full Scale. }}$

$$
m_{t} \ddot{P}_{m}+C_{t} \dot{P}_{m}+k P_{m}=k P_{i}
$$

In practice the small mass of the diaphragm can be neglected since the resulting natural frequency is far above any frequency of interest in a hydraulic system. With this approximation Eq. 10 becomes,

$\dot{P}_{m}(t)+\frac{P_{m}(t)}{T_{r}}=\frac{P_{i}}{T_{r}}$ 
Where $P_{i}$ is the pressure at the transducer manifold or port and $T_{r}$ is the transducer rise time given by $C_{t} / k$. The transform of Eqn. 11 is,

$$
\frac{P_{m}(S)}{P_{i}(S)}=\frac{\frac{1}{T_{r}}}{\left(S+\frac{1}{T_{r}}\right)}
$$

The inverse transform of Eqn. 12 is $1 / \operatorname{Tr} \exp (-t / \operatorname{Tr})$. This function is the impulse response to Eqn. 11 which will be needed shortly. Multiplying Eqn. 12 by its complex conjugate and taking the square root, the transfer function relating $\mathrm{P}_{\mathrm{m}}$ to $\mathrm{P}_{\mathrm{i}}$ is,

$$
\left.R_{2}(f)=P_{m}(f) / P_{i}(f)=1 / 11+\left(2 \pi f T_{r}\right)^{2}\right]^{1 / 2}
$$

The response of any given transducer can now be described as the product of the two transfer functions, $R=R_{1}(f) R_{2}(f)$.

$\mathrm{R}=1 /\left\{\left[1-\left(\mathrm{f} / \mathrm{f}_{\mathrm{n}}\right)^{2}\right]^{2}+(2 \pi f \tau)^{2}\right\}^{1 / 2} \mathrm{X}$ $1 /\left\{1+\left(2 \pi f T_{r}\right)^{2}\right\}^{1 / 2}$

The response of a typical system with $1 / 4$ in lines, 30 feet long and a transducer with a rise time of $0.1 \mathrm{sec}$ is illustrated in Figure 2. Both undamped and damped responses are pictured.

If the manifold pressure $P_{i}$ in Eqn. 11 were a constant, the pressure measured by the transducer would simply be,

$$
P_{m}(t)=P_{i}\left[1-\exp \left(-t / T_{r}\right)\right]
$$

However, a general solution to Eqn. 11 is sought where the manifold pressure $P_{i}$ is given by Eqn. 6, the time dependent response of the first system partition, which subsequently becomes the driving function for the second partition described by Eqn. 11. The general solution to Eqn. 11 can be written as, $P_{m}(t)=P_{0}\left[1-\exp (-t / \tau) \cos \omega_{r} t\right] *\left[1-\exp \left(-t / T_{r}\right)\right]$

which is simply obtained by convolving the driving function, Eqn. 6 , with the impulse response noted above. This function is illustrated in Figure 3 for a system having the frequency response shown in Figure 2.
The separation of the system into two partitions was convenient to describe the parallel connection of multiple transducers. In the case of a single transducer the response function is just $R_{1}(f)$ with $\tau$ representing the total system response time including the rise time of the transducer and the damping forces in the lines. Also $\mathrm{k}_{\mathrm{eff}}$ is simply the $\mathrm{k}$ of the transducer. This result points out the important fact that the system response function will be different when multiple transducers are connected in parallel.

\section{Development of Model Parameters}

\section{Natural Frequency}

One of the most important parameters for determining the dynamic response of any transducer is the spring constant which along with the mass of the fluid in the transmission lines determines the natural resonant frequency. The mass parameter is easy to calculate once the length and diameter of the lines are known. The information to determine the spring constant is more difficult to obtain. The spring constant $\mathrm{k}_{\text {eff }}(\mathrm{lbf} / \mathrm{in})^{\circ}$ is derived from the full scale $\Delta P / \Delta V$ rating of each of the transducers. For each transducer $k=A^{2}$ $\Delta \mathrm{P} / \Delta \mathrm{V}$ where $\mathrm{A}$ is the active diaphragm area. In principle the spring constants should sum in parallel but the active areas are likely to all be different. For this reason, when multiple transducers are installed in parallel it can be difficult to estimate the natural frequency.

In the case of a single transducer, the active diaphragm area cancels in the differential pressure equation leaving $\Delta \mathrm{P} / \Delta \mathrm{V}$ to be determined. The full-scale displacement volume is sometimes quoted by manufacturers as less than or equal to a certain value. A value of $0.01 \mathrm{in}^{3}$ is typical for a number of diaphragm type transducers. For a full scale rating of 20 Psi. this yields a $\Delta \mathrm{P} / \Delta \mathrm{V}$ value of $2000 \mathrm{Psi} / \mathrm{in}^{3}$. Using water at about $80^{\circ} \mathrm{F}$ and $1 / 4$ in diameter lines $20-60$ feet long, resonant frequencies are in the range 3-7 Hz. These frequencies are quite 
near to frequencies of interest $(0-2 \mathrm{~Hz})$ in hydraulic systems.

Because of its importance, the best practice is to measure the natural resonant frequency of the transducer when it is installed in the loop. A quick acting solenoid valve may be used to apply a pressure stepfunction to the system. If the system has a significant resonance, it is a simple matter to determine the frequency from a plot of the response such as that shown in Figure 3. This measurement must be made with a transducer having a fast enough response time to follow the oscillation. Such measurements will be shown in a later section of this report.

\section{Damping Parameters}

Damping in any real system can be difficult to estimate. One known source of damping is the frictional force in the instrument lines. This viscous force is proportional to the velocity of the fluid and is given by,

$$
F_{t}=C * V=\frac{f_{u}}{4} * \frac{|V|}{2 g_{0}} \pi \rho d L * V .
$$

Taking $f_{u}$ in the laminar flow limit as $64 / R_{e}$ the velocity coefficient, $\mathrm{C}$, becomes $8 \pi \mu \mathrm{L} / \mathrm{g}_{0}$. Dividing by the mass, an estimate of the damping due to the viscous forces is,

$\beta_{v} / 2=16 v / d^{2}$

Assuming 1/4 in diameter lines containing, for example, the modeling fluid HFC-134a, the calculated damping $\beta / 2$ is only about $0.14 \mathrm{sec}^{-1}(7.1 \mathrm{sec})$. Comparison with experimental measurements, which are made in the next section of this report, show that this value is too small to provide critical damping $\left(\beta_{\text {crit }}=4 \pi f_{n}\right)$ in a practical system.

In addition to the viscous forces, damping will be created by system components, such as orifices, having an unrecoverable pressure loss given by,

$$
\Delta P=K \frac{\rho V^{2}}{2 g_{0}}
$$

As with the viscous force, the coefficient of the velocity term can be identified and divided by the mass to obtain an estimate of the damping.

$$
\beta_{\Delta P} / 2=\frac{K}{4} \frac{V}{L}
$$

where $L$ is the length of the fluid transmission lines and $\mathrm{V}$ is the velocity of the fluid. The fluid velocity may be approximated by $\Delta \mathrm{L} / \Delta \mathrm{t}$ where $\Delta \mathrm{L}$ is the peak-to-peak displacement of the fluid in the lines and $1 / \Delta t$ is the resonant frequency, $f_{n}$. This yields an estimate of the damping due to irrecoverable pressure losses given by,

$$
\beta_{\Delta P} / 2=\frac{K}{4} f_{n} \frac{\Delta L}{L}
$$

This equation can be used to select an orifice with a $\mathrm{K}$-loss factor appropriate to provide the desired damping at the resonant frequency.

\section{Comparison with Experimental Data}

\section{Previous Measurements Made in Facility-1}

After modifications were made to one of our facilities in 1992 and again in 1994 , measurements were made of the step-function pressure response using a 20-psi full-scale Viatran transducer. The results showed a damped oscillation at about $5.9 \mathrm{~Hz}$ (See Figure 4). The pressure transmission lines consisted of about 20 $\mathrm{ft}$ of $1 / 4$ in hard line plus $20 \mathrm{ft}$ of $1 / 4$ in flexible line. The manufacturer of the Viatran units quotes a $\Delta V$ value of $\sim 0.01$ in $^{3}$ which leads to a $\Delta P / \Delta V$ value of $2000 \mathrm{psi} / \mathrm{in}^{3}$ Using these parameters in the model the calculated response shows a resonance at about $6 \mathrm{~Hz}$. This level of agreement is very good.

\section{Recent Facility-2 Measurements}

A series of measurements of the transient response of multiple pressure transducers installed in another facility was recently performed in order to confirm the present model and to measure the key parameters. The initial measurements used three transducers connected in parallel; 
a 10 psi Druck model LP-9000, a 10 psi piezoelectric based Druck model PTX-2110 and a 27 psi Rosemount model 1151. The response times for these three transducers were stated as $0.0005 \mathrm{sec}$ for the piezoelectric Druck model, $0.010 \mathrm{sec}$ for the Druck diaphragm unit and $0.3 \mathrm{sec}$ for the Rosemount. The spring constant associated with each unit was more difficult to evaluate. The active area of each unit was different and not well known. Because of this, the effective spring constant associated with the three units connected in parallel could not be calculated. Instead, the resonant frequency was measured and the spring constant derived from this result.

The test was performed using a fastacting, solenoid-actuated, flow equalization valve to rapidly interrupt the flow to provide a sharply defined pressure step-function to the system. The results obtained are shown in Figure 5.The trace of the interrupted flow rate can be seen in the lower left-hand corner of the graph. The other three traces represent the voltage outputs of the three transducers. (They have different scale factors and voltage spans so they can not be directly compared.) The shape of the pressure response for the two faster units is very similar. The rise time for the Rosemount unit $(\sim 0.3 \mathrm{sec})$ is about $30 \mathrm{X}$ longer than the other two transducers. The important result is that all three units show a common resonant frequency of about 2.0 $\mathrm{Hz}$. Using this measured value and the known mass of the fluid in the lines, an effective spring constant, $\Delta \mathrm{P} / \Delta \mathrm{V}$, of about $455 \mathrm{Psi} / \mathrm{in}^{3}$ can be estimated.

The fact that this system has a resonant frequency at $2 \mathrm{~Hz}$ would make this arrangement unacceptable for the measurement of frequencies near this value. It would be necessary to use shorter and/or larger diameter lines or to select a transducer with a larger spring constant in order to place the resonant frequency well above the frequencies of interest (see Eqn.7).

The measured response in Figure 5 can also be used to estimate the actual damping in the system. Using Equation 6 and trial values for the damping, a response is calculated which matches the ring down time of the oscillation. A reasonably good approximation for the Druck units is shown in Figure 6.This leads to an estimate of 2.38 $\mathrm{sec}^{-1}$ for the system damping. As noted earlier, this is much greater than the damping due only to the viscous forces in the lines. However, additional damping, such as the use of flow restricting orifices would be necessary before this system could be used for accurate measurements. The system should be designed to have near critical damping without excessive ringing. The ringing not only distorts the measurement but may also overrange the transducer.

Figure 7 shows the calculated timeresponse function after the damping has been increased to $12.5 \mathrm{sec}^{-1}$ which is approximately equal to the critical damping. Ringing at the resonant frequency has been eliminated. However, it is also necessary to examine the frequency response to verify that the gain curve is acceptably close to unity at the frequencies to be measured. Figure $8 \mathrm{a}$ illustrates the frequency response associated with this $12.5 \mathrm{sec}^{-1}$ value of the damping. Notice that the system is indeed critically damped at the resonant frequency of $2 \mathrm{~Hz}$. However, this leads to underdamping (system gain) at frequencies below $2 \mathrm{~Hz}$. This graphically illustrates the difficulty of having the natural frequency too close to the frequencies of interest. If the damping is now further increased to provide the flattest frequency response up to the highest possible frequency, the system will necessarily become overdamped at the resonant frequency as shown in Figure $8 b$.

In a second series of measurements, the same three transducers were connected to the system one at a time and the response to a step-function pressure change was again determined. The results were significantly different. Figure 9 shows the measured response of the Druck piezoelectric unit by itself. The system resonant frequency has shifted up to about $6.3 \mathrm{~Hz}$. This clearly demonstrates that the resonant frequency can be affected by connecting transducers in parallel. The high frequency noise that now 
appears in the response is at least partially electrical in origin. The visibility of these high frequencies is the result of the fast response time of this transducer. Electronic filtering will remove this noise.

This second series of measurements was also performed with an additional 20 feet of flexible instrument line relative to the first measurements. The calculated model fit to the data shown in Figure 9 indicates that the additional flexible line has increased the system damping. The previous value of 2.38 $\mathrm{sec}^{-1}$ is now about $6.7 \mathrm{sec}^{-1}$. It appears that the use of flexible lines is one way to increase the system damping. It is also important to recognize that using a low mass, fast response transducer such as the Druck unit is a good way to measure the effective system damping since this fast response transducer contributes negligible additional damping to the system.

As Figure 9 shows, additional system damping is still required in order to prevent ringing. With critical damping applied at 6.5 $\mathrm{Hz}$, the result (shown in Figure 10) looks similar to that shown in Figure 7 but once again the frequency response below $6.5 \mathrm{~Hz}$ is greater than unity. With a small amount of overdamping at $6.5 \mathrm{~Hz}$, the frequency response gain-curve shown in Figure 11 can be achieved. This result is quite acceptable for frequencies up to $4-5 \mathrm{~Hz}$.

Figure 12 shows the pressure response of the Druck diaphragm transducer when used by itself. For this case the resonant frequency is about 2.1 $\mathrm{Hz}$, which is slightly greater than the resonant frequency obtained with all 3 transducer units in parallel. This suggests that the $\mathrm{k}_{\text {eff }}$ for all three units in parallel is about the same as that of the Druck diaphragm type transducer alone. Finally Figure 13 shows the measured response of the Rosemount transducer by itself. This system is so highly damped that the natural frequency can not be seen in the measured response.

\section{Summary}

It has been shown that the length and diameter of pressure transmission lines between a transducer and the pressure source can significantly affect the dynamic frequency response. In this paper, a lumped-parameter, spring-massdamper model of a multiple transducer and pressure line system was adapted from an earlier, simpler model in the literature. The model was compared with measurements of the step-function pressure response of various transducers. With the aid of the model, the actual system resonant frequency and damping was determined from the measurements. Additional damping was added to the model to prevent ringing of the signal and a new system pressure response and frequency response curve was calculated. It was shown that when the natural resonant frequency is sufficiently above the desired range of frequencies, a flat gain curve could be developed.

This paper also includes a derivation of the damping due to the viscous forces in the pressure transmission lines. When compared with measurements, this source of damping alone is too small to explain the actual damping. There appears to be other dissipative forces associated with the system, which contribute additional damping. In practice, the system damping will need to be measured.

For all of the experimental systems evaluated in this report, the response at the natural frequency was significantly underdamped and ringing was observed. This means that in order to perform accurate measurements, damping needs to be added to the system to increase the total damping to approximately the critical value. It was observed that the use of flexible pressure lines versus hard lines does increase the damping and may 
therefore be useful in certain situations. An equation was also developed which will permit sizing an orifice that could be added to the system to provide the necessary critical damping.

\section{Acknowledgements}

We are grateful to Mr. W.O. Morris for quickly and skillfully performing the transducer pressure response measurements including the follow-up measurements with only single transducers connected in the manifold. We also thank Mr. M.A. Gosden for his critical reading of this report.

\section{Reference}

1. W.L. Zabriskie, S.C. Rogers, G.N. Miller and K.G. Turnage, "Instrumentation Development for Low Range, Long Line Differential Pressure Measurements", ORNL paper presented at 26'th Annual International Instrumentation Symposium, Seattle WA 1980, ISA Transactions, Vol. 20,No. 4, p-61, 1982. 


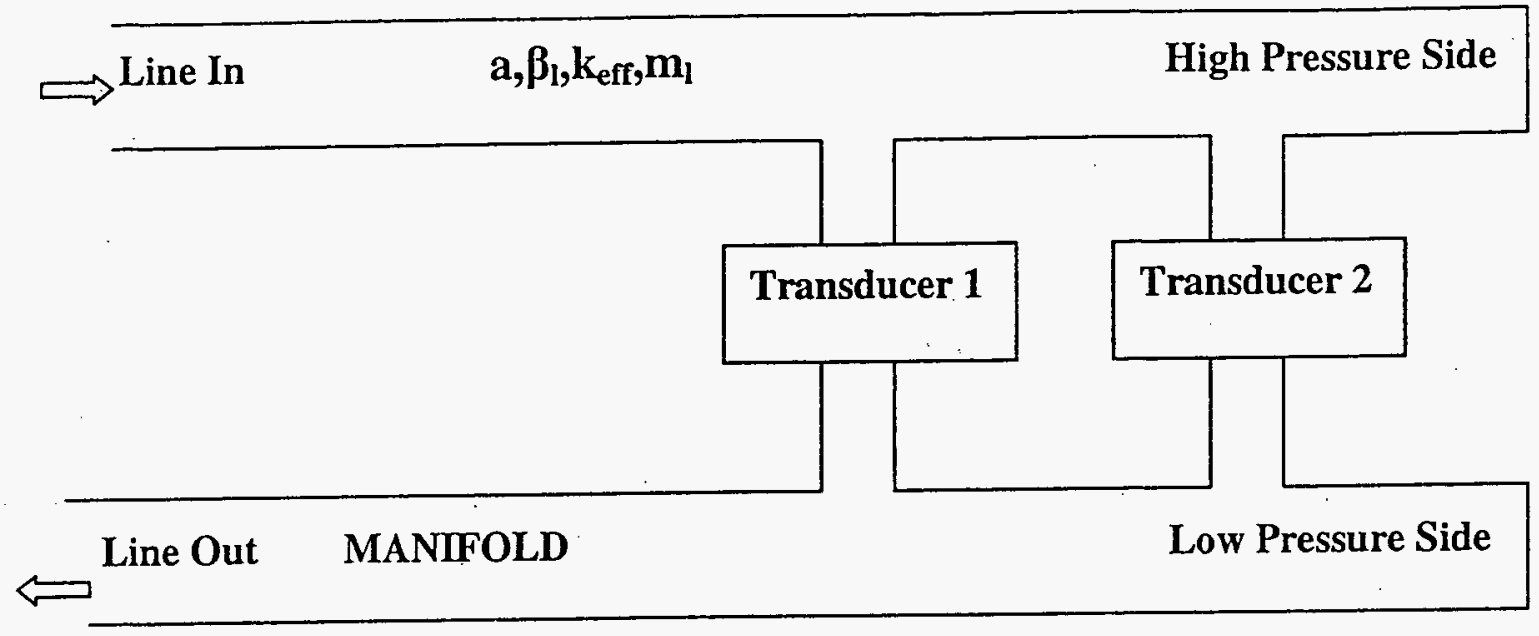

Figure 1a High and Low Pressure Transducer Lines and Manifold

Figure 1b Equivalent Single-Line Absolute Pressure Schematic 


\section{System Response}

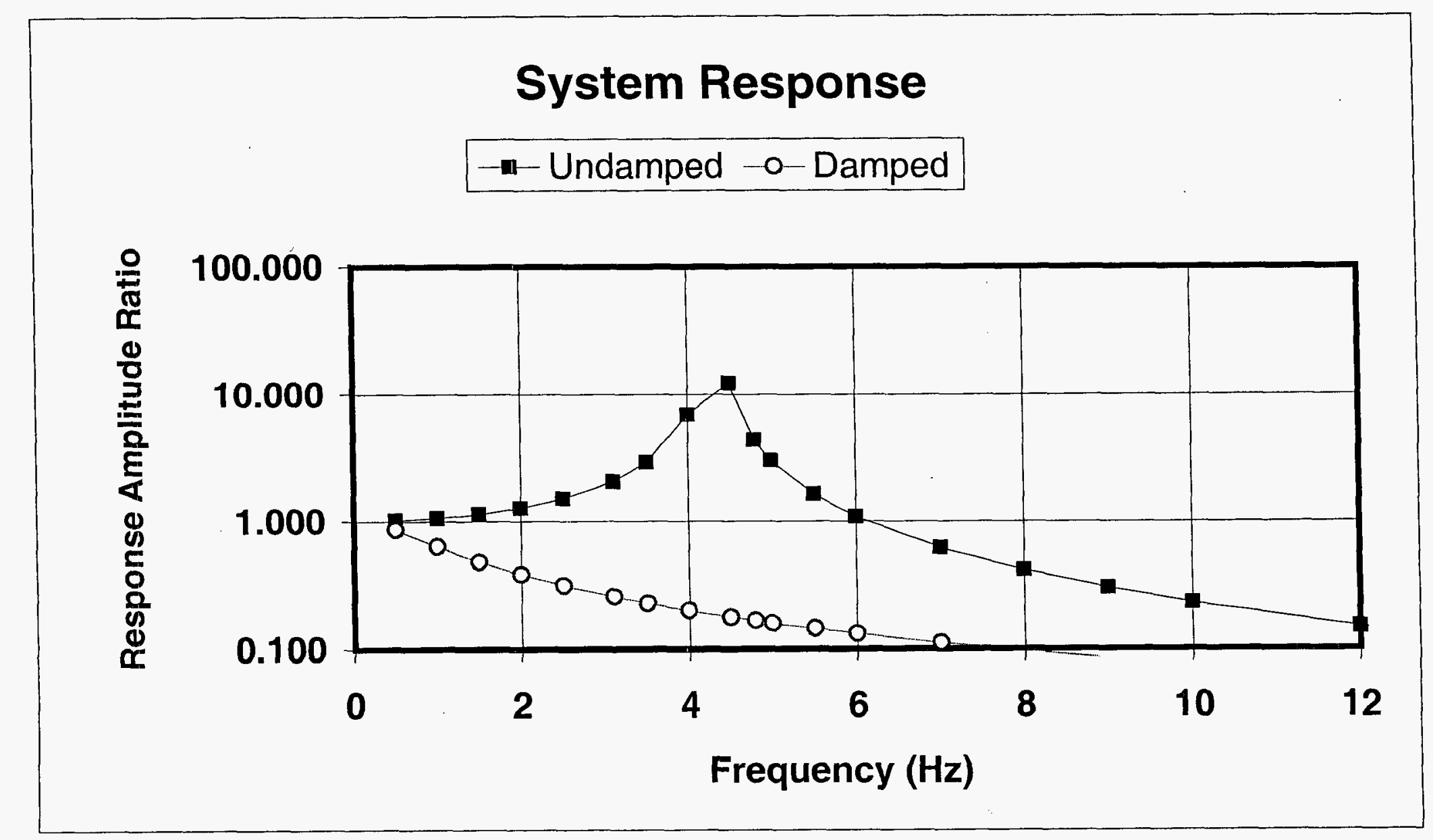

Figure 2 Damped and Undamped Response with $30 \mathrm{Ft}$. Lines 


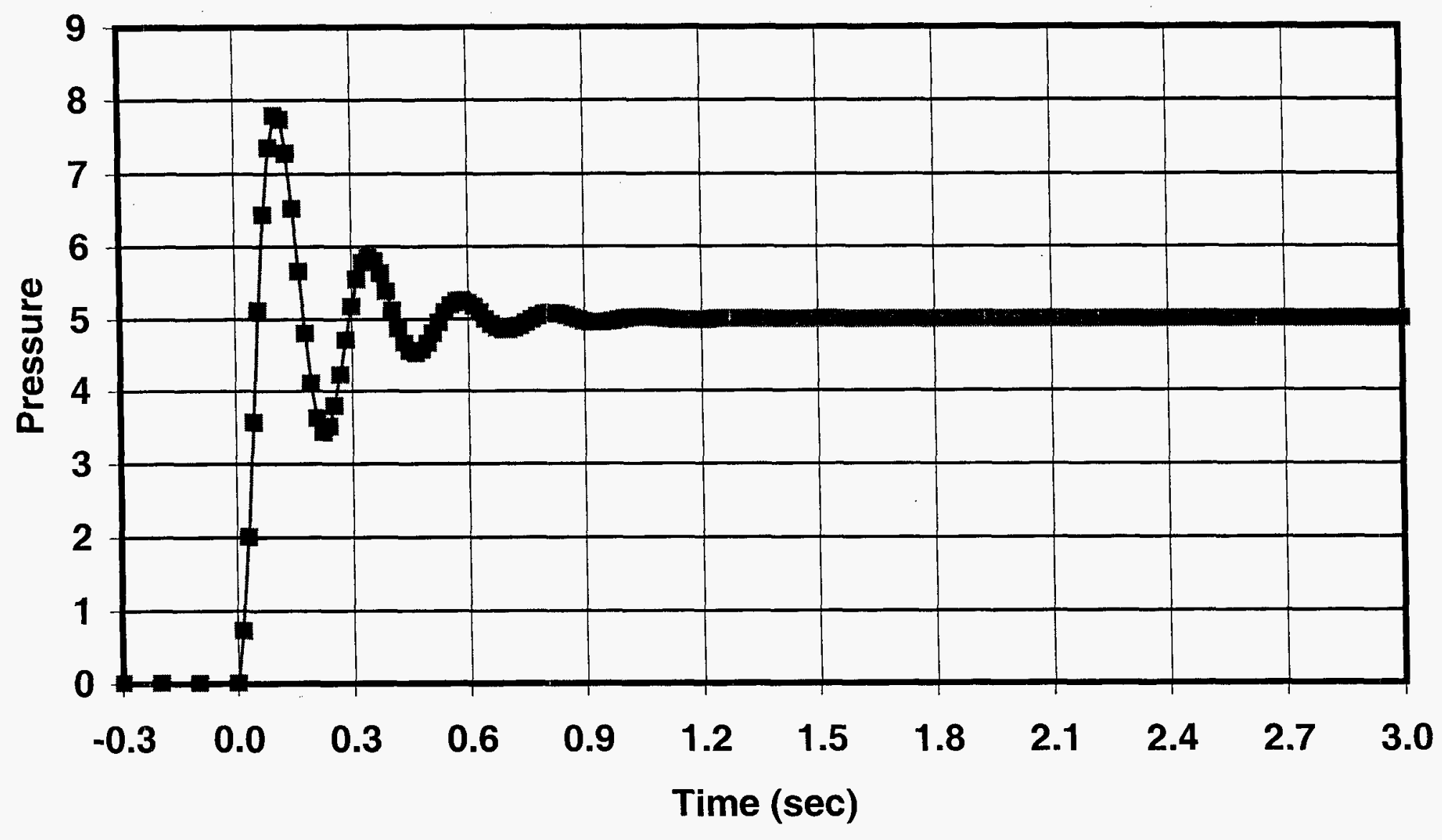

Figure 3 Time Domain Response to a 5 Psi Step-Function 
Figure 4

Average Period is $0.17 \mathrm{sec}(5.9 \mathrm{~Hz})$

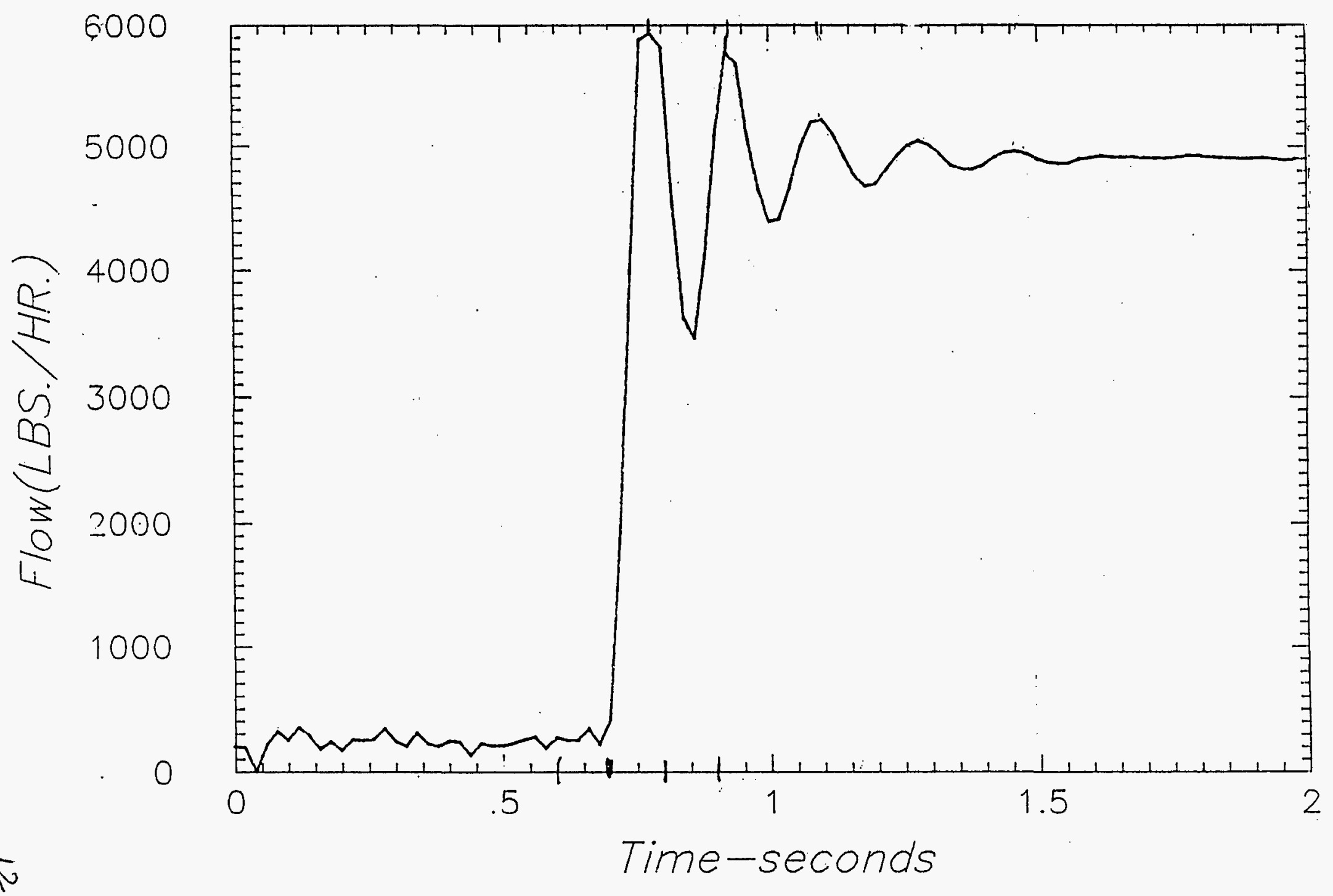

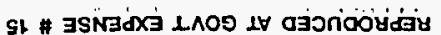




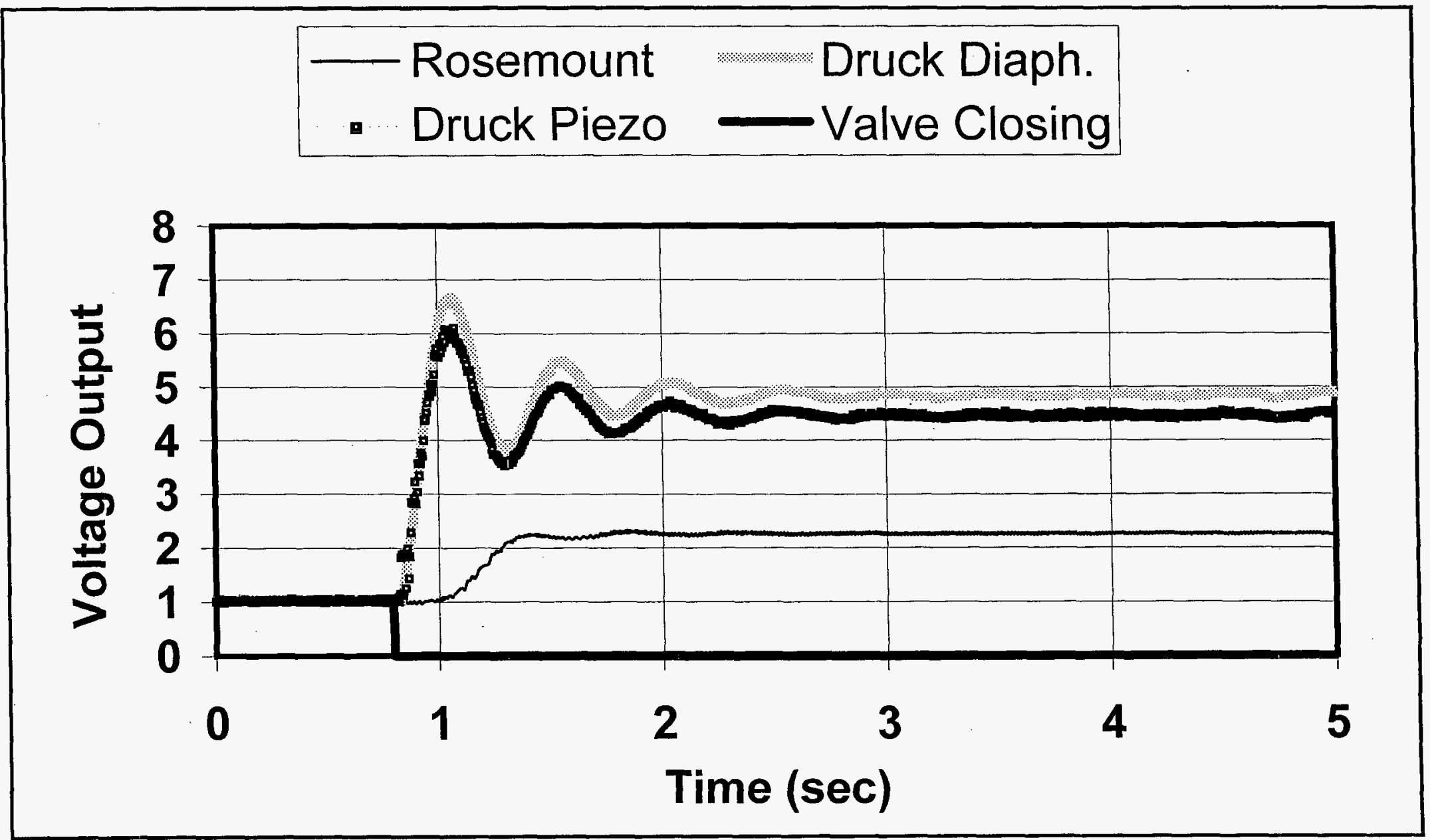

Figure 5 Pressure Step-Function Response---Three Manifolded Transducers 


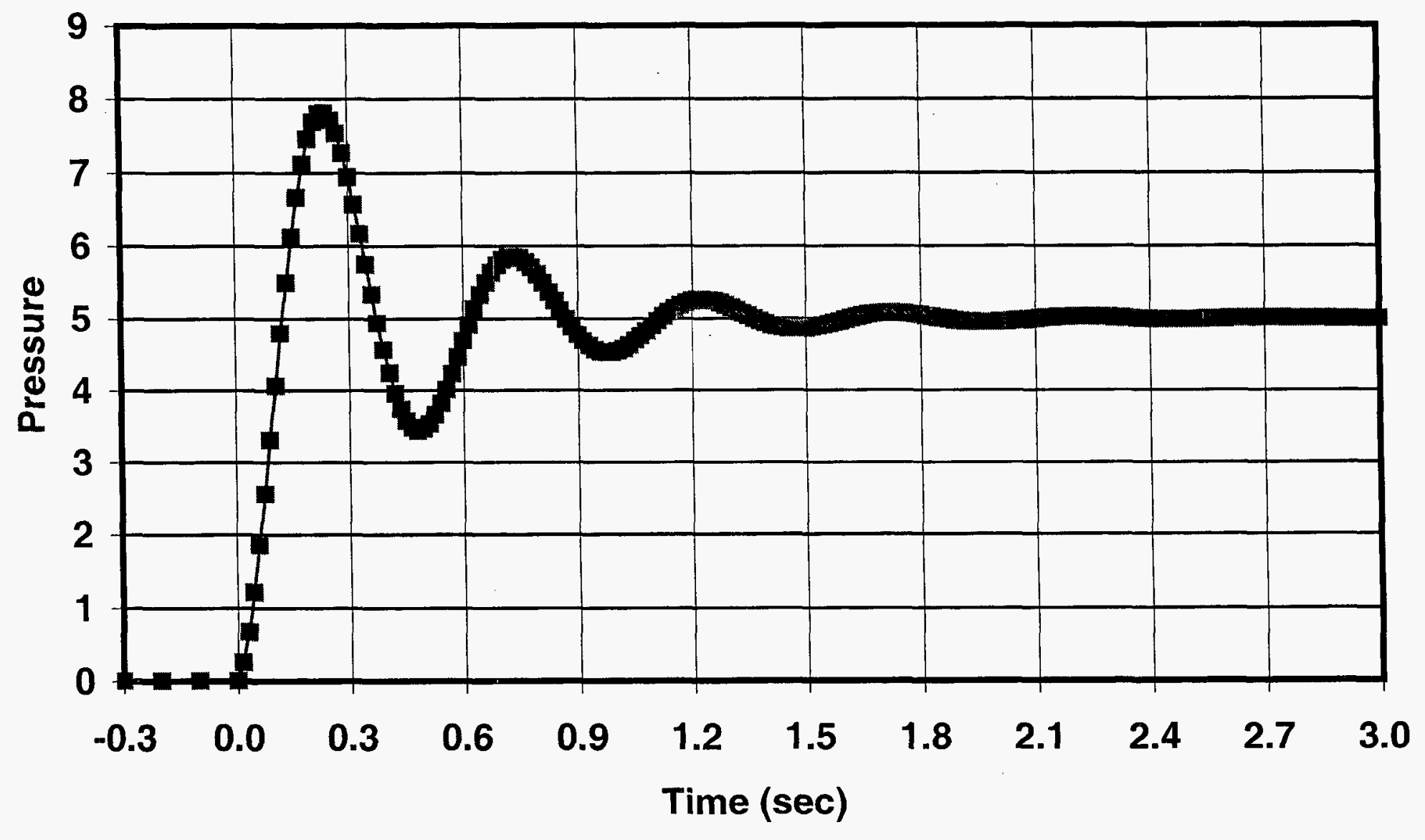

Figure 6 Simulation of Measured Step-Function Pressure Response 


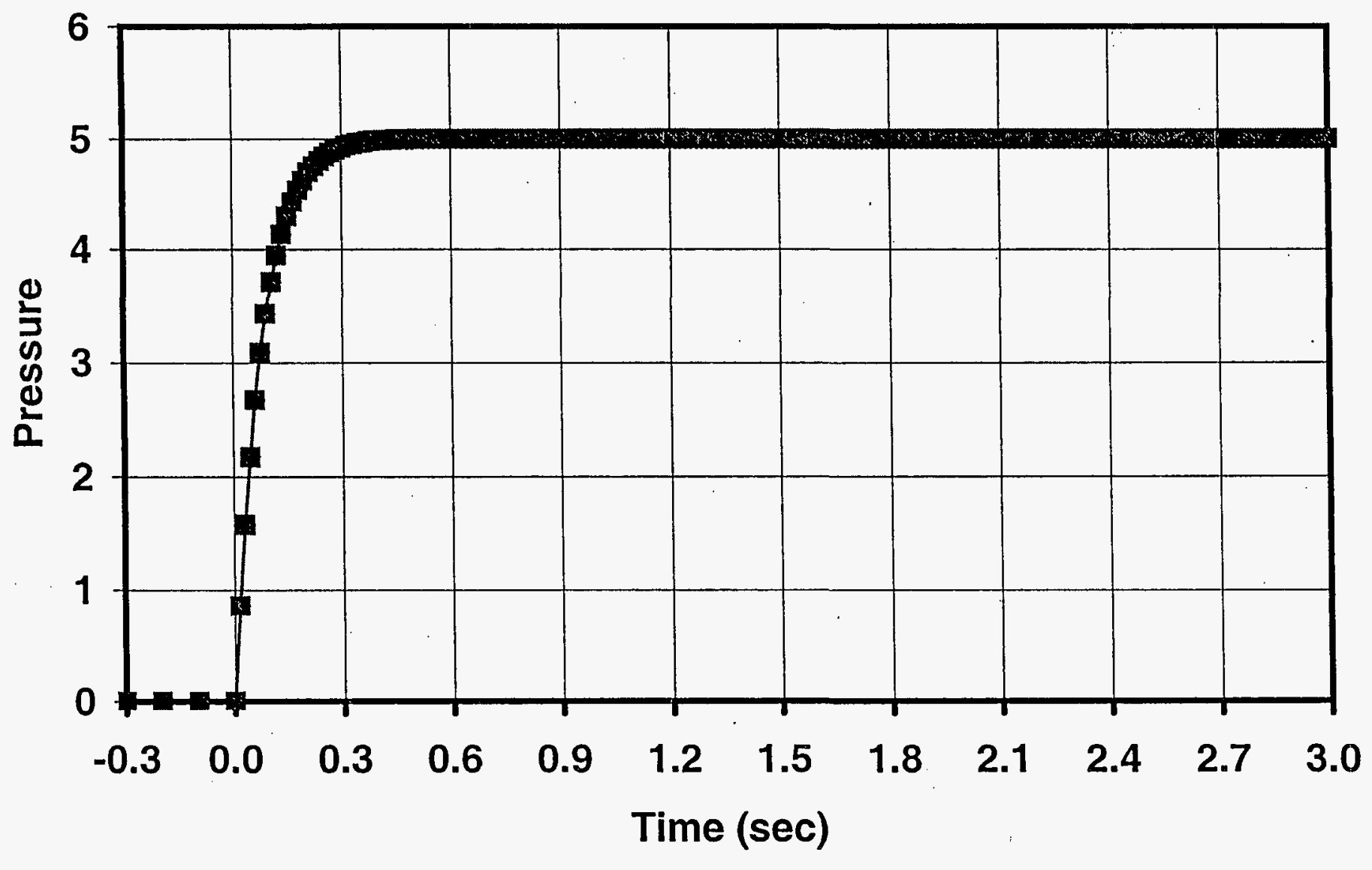

Figure 7 Simulated Pressure Response with Critical Damping Applied 


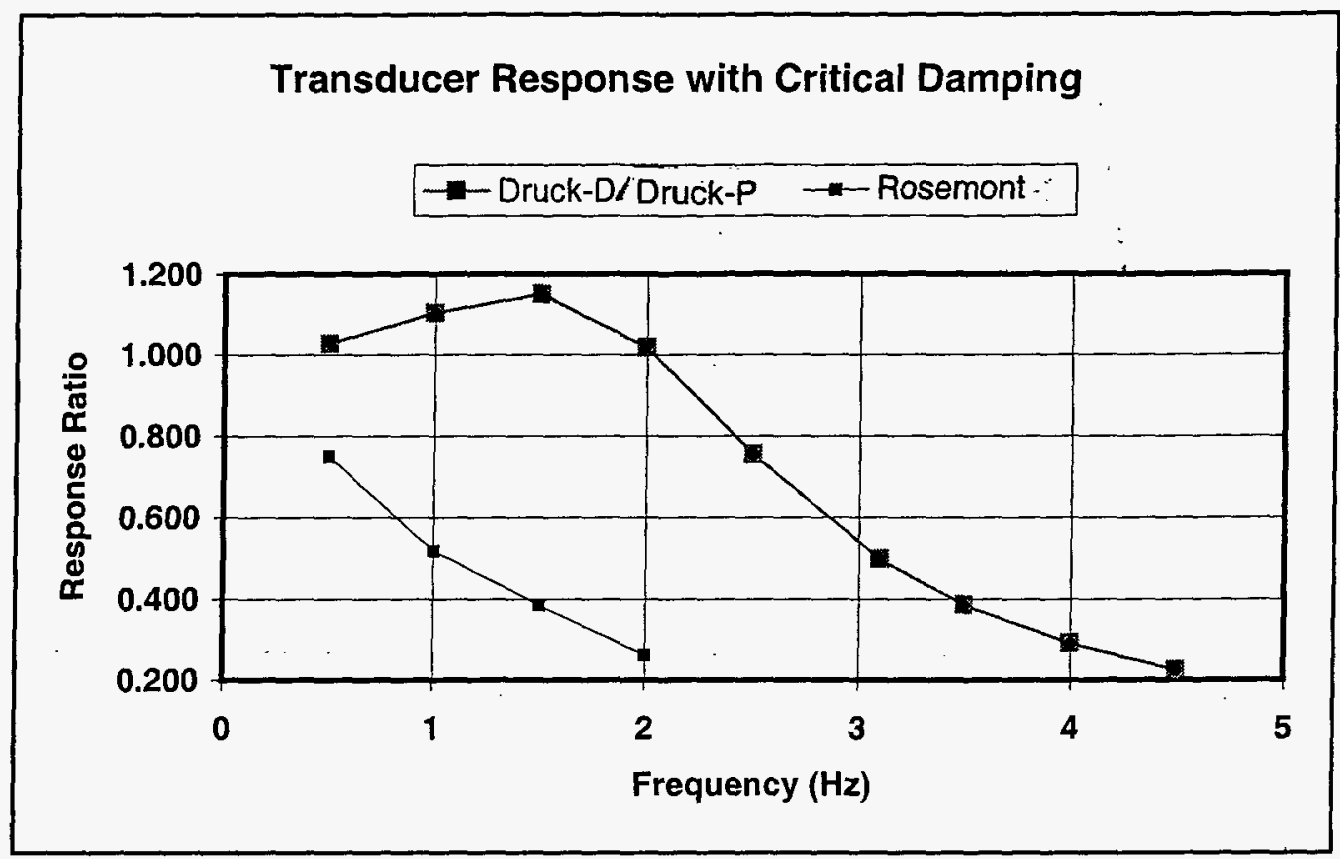

Figure 8a Simulated Frequency Response with Critical Damping at the Natural Resonant Frequency

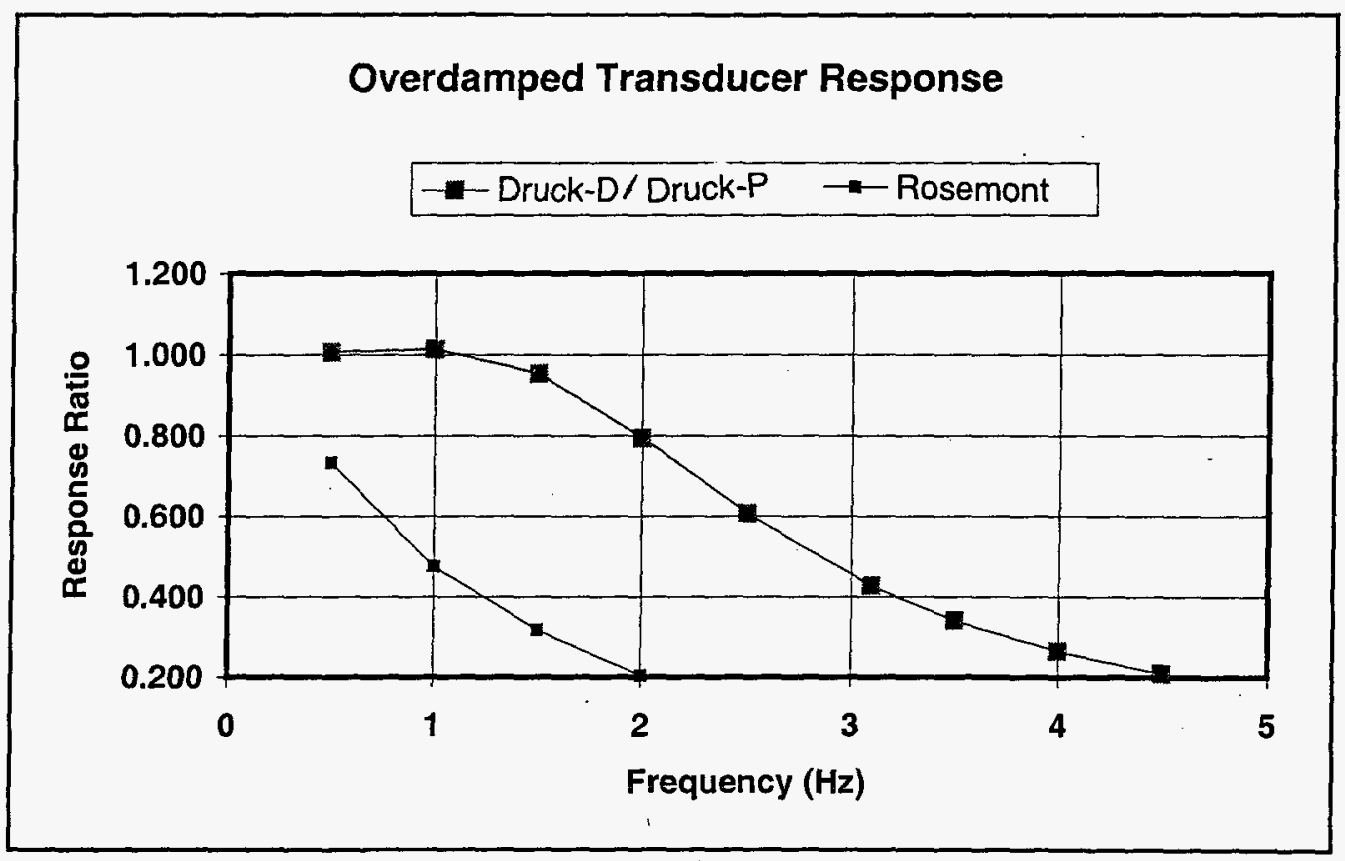

Figure 8b Simulated Frequency Response Overdamped at the Resonant Frequency---(Flattest Gain Curve) 


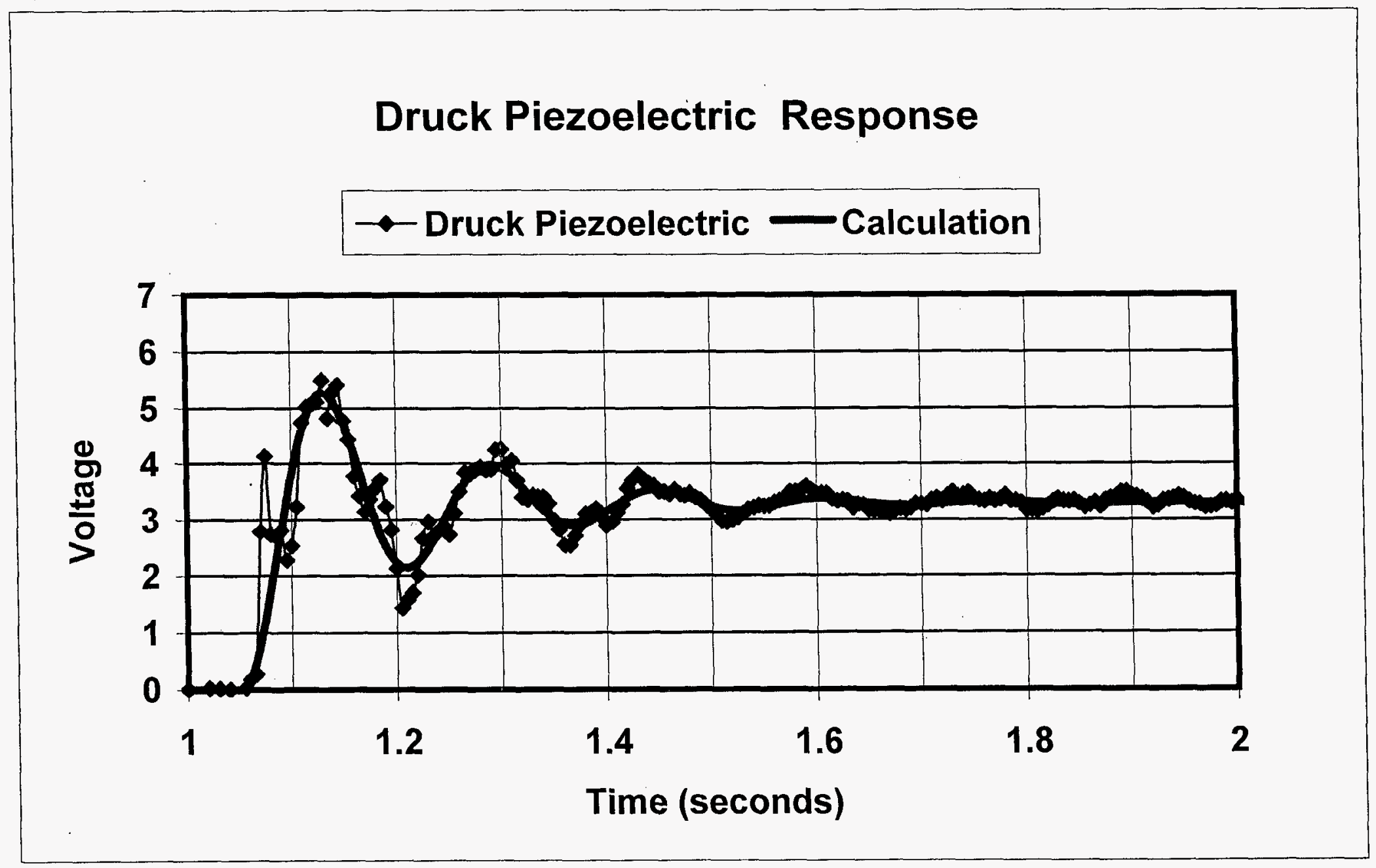

Figure 9 Druck Piezoelectric Transducer Alone Solid Curve is Model Calculation 


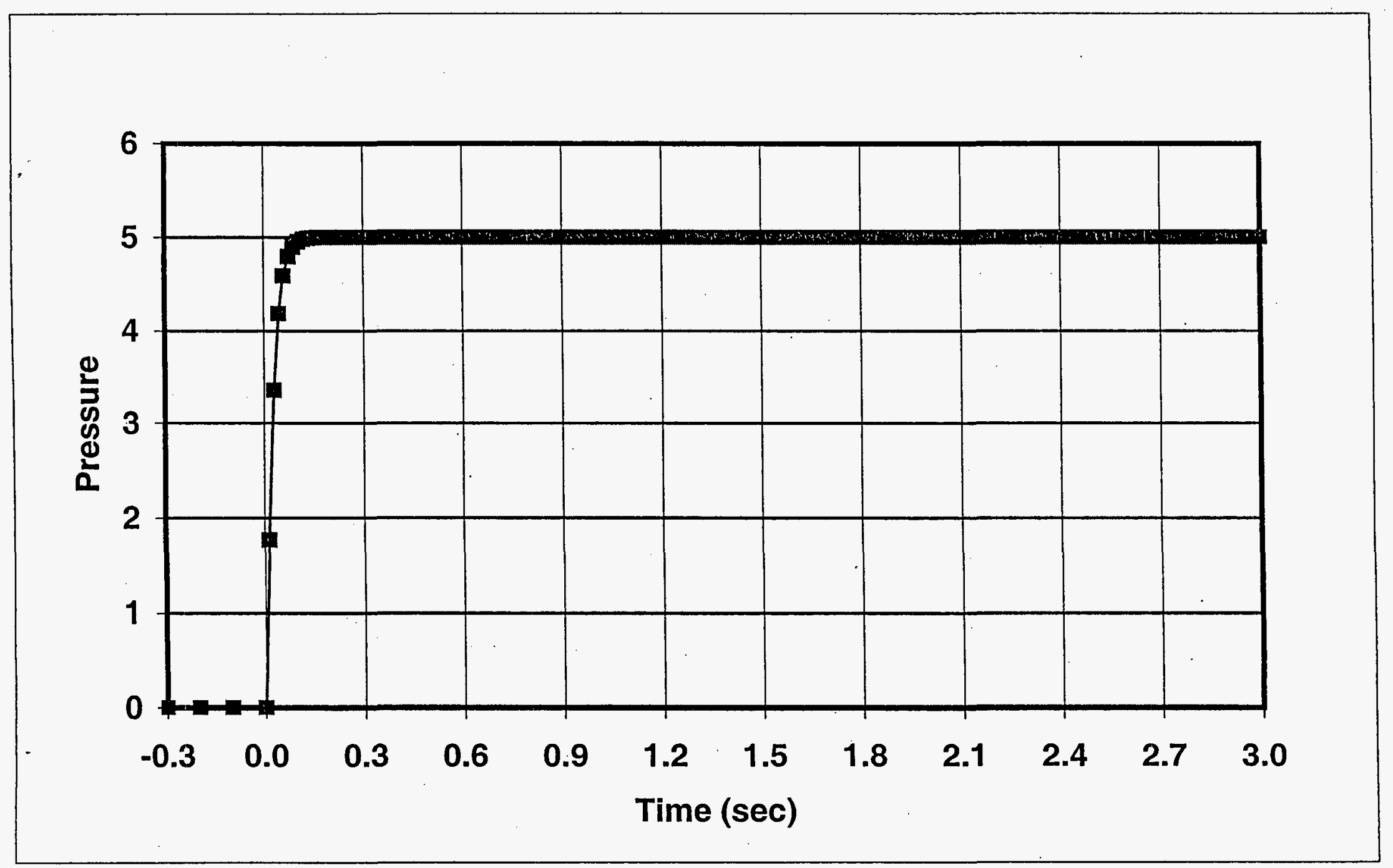

Figure 10 Simulated Pressure Response with Critical Damping Applied 


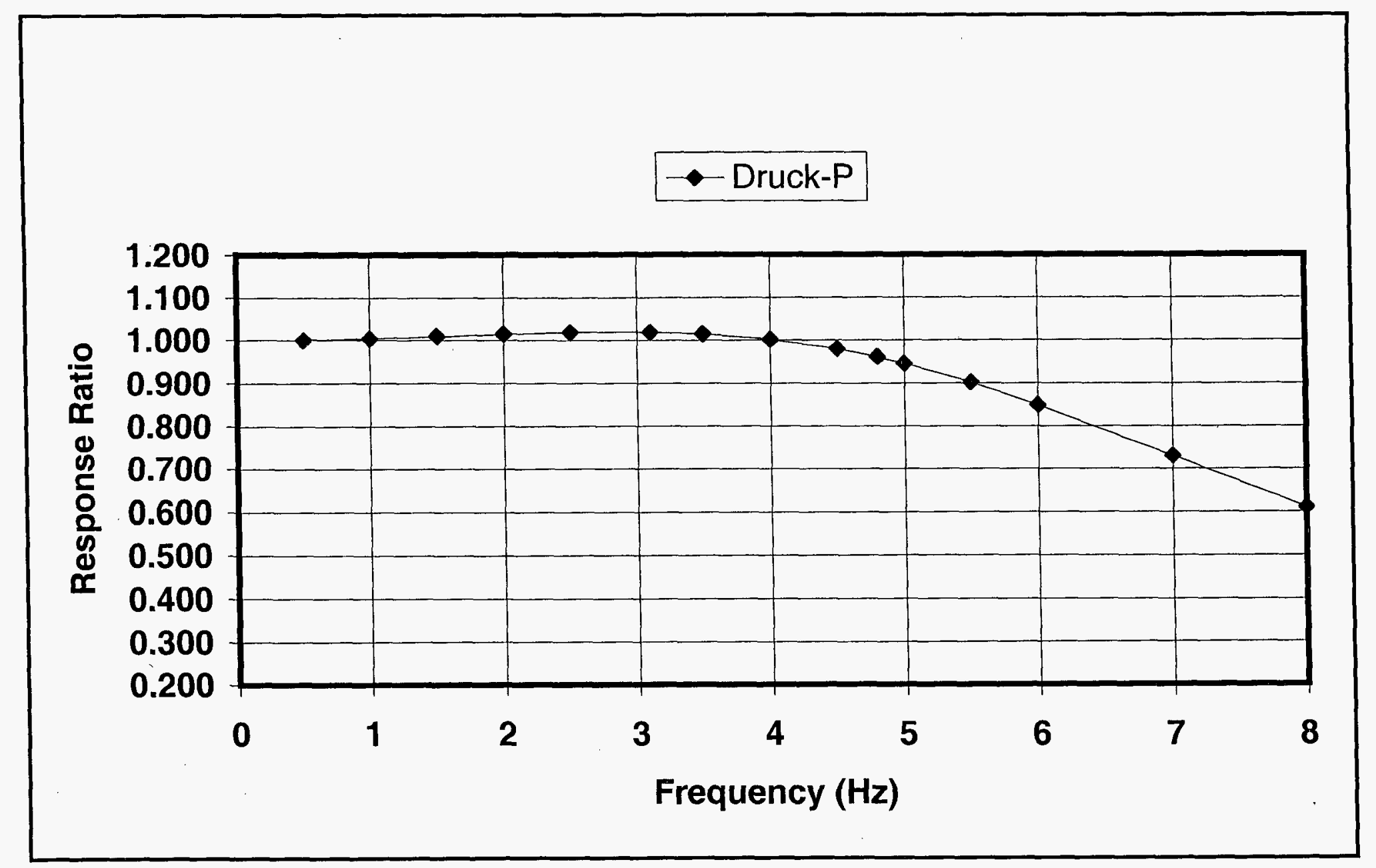




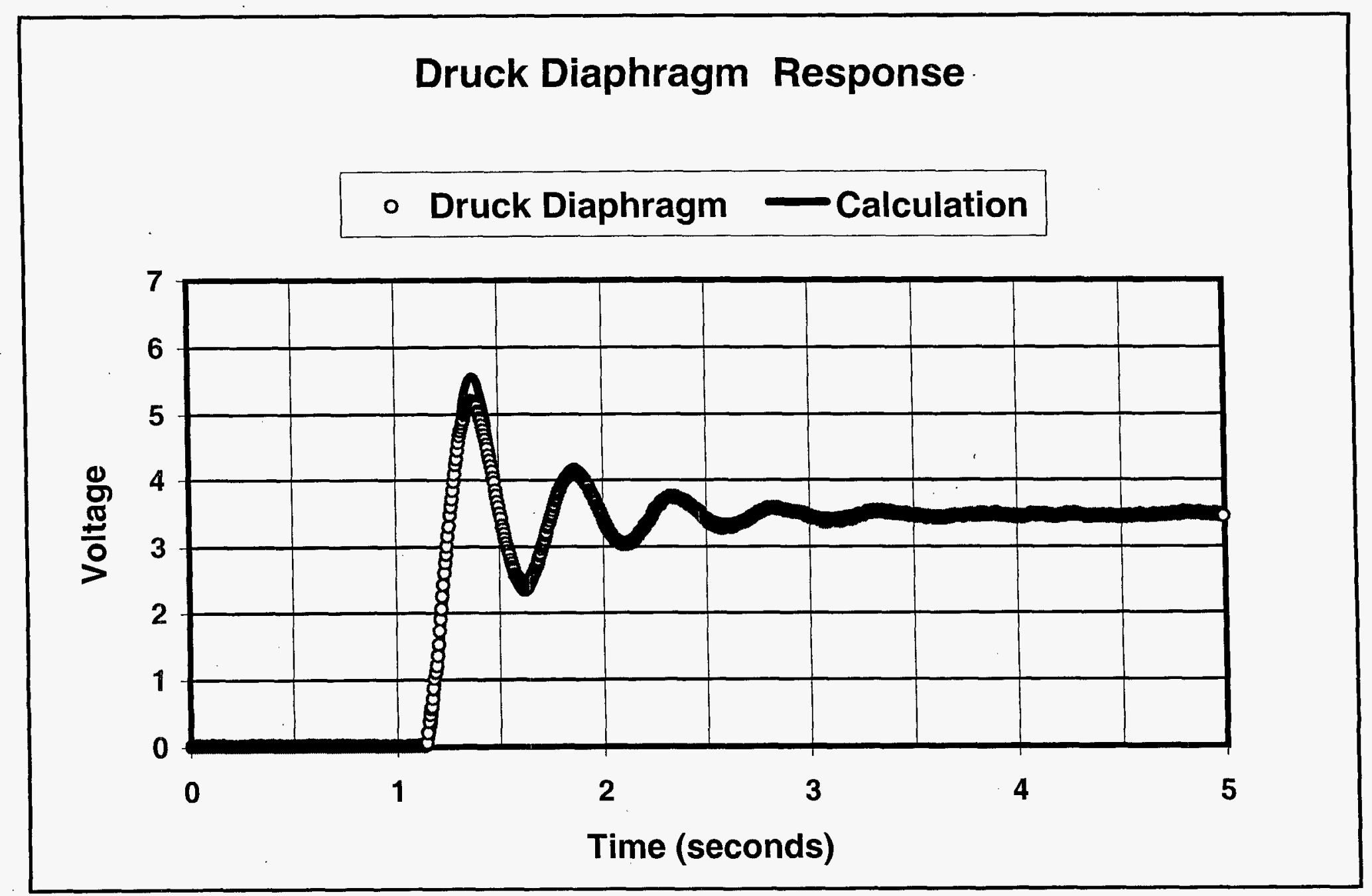

Figure 12 Druck Diaphragm Transducer Alone 


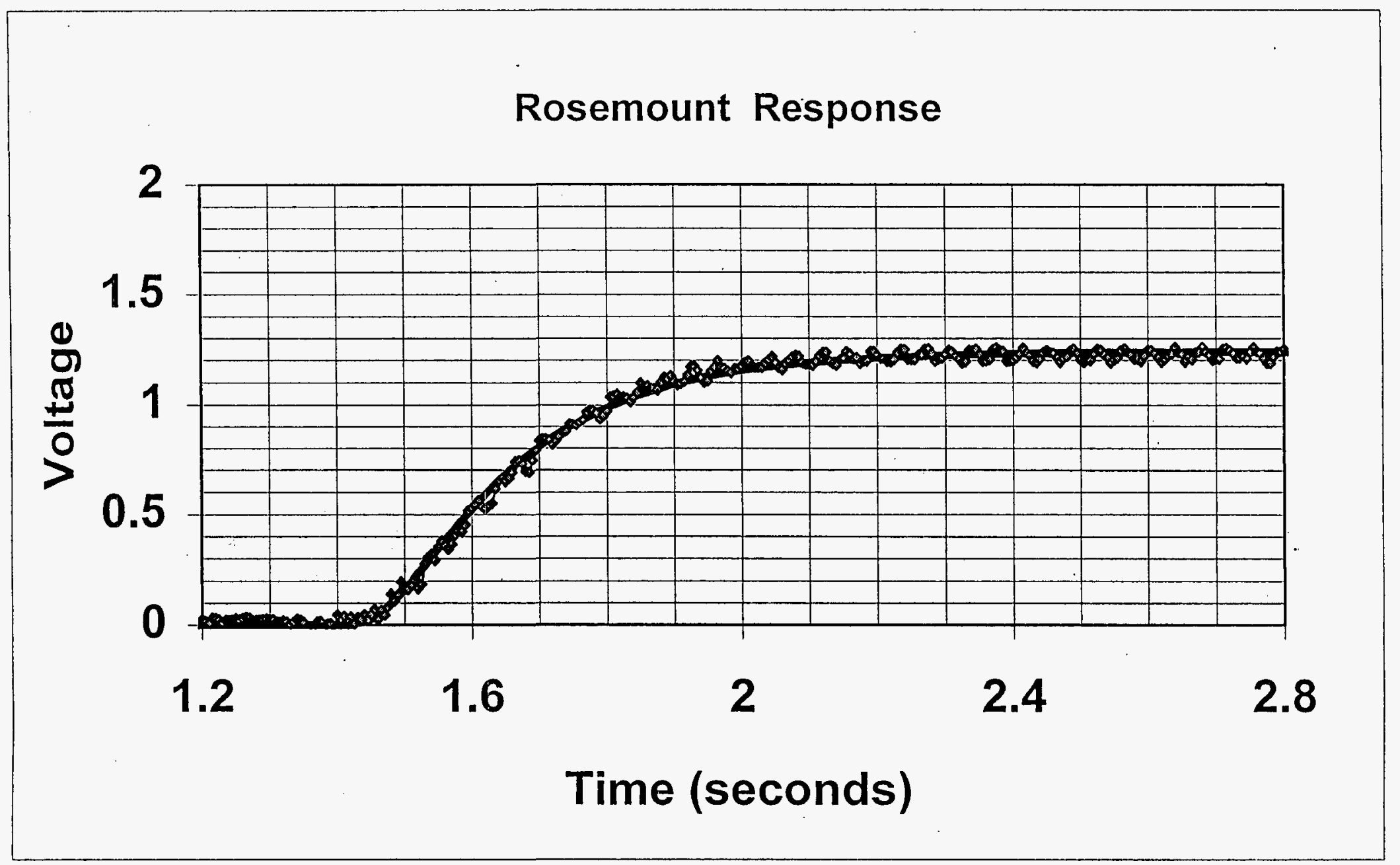

Figure 13 Rosemount Transducer Only 